Article

\title{
Syntheses of Novel Coordination Polymers Using Bis-Imidaz- ole Ligand Having Steric Hindrance and Methoxy Group
}

\author{
Billy Oktora Abdilah Fauzi ${ }^{1,}{ }^{*}$, Mitsuru Kondo ${ }^{1,2}$ \\ ${ }^{1}$ Department of Chemistry, Graduate School of Integrated Science and Technology, Shizuoka University, Shi- \\ zuoka, Japan \\ ${ }^{2}$ Green Bio Research Division, Research Institute of Green Science Technology, Shizuoka University, Shizuoka \\ *Correspondence: billy.oktora.a.fauzi.18@shizuoka.ac.jp
}

How to cite this paper : Fauzi, B. O.

A., \& Kondo, M. (2021). Syntheses of Novel Coordination Polymers Using Bis-Imidazole Ligand Having Steric Hindrance and Methoxy Group. Online Journal of Chemistry, 1(1), 29-

37. Retrieved from

https://www.scipublica-

tions.com/journal/index.php/ojc/article/view/84

Received: July 6, 2021

Accepted: August 13, 2021

Published: August 14, 2021

Copyright: () 2021 by the authors. Submitted for possible open access publication under the terms and conditions of the Creative Commons Attribution (CC BY) license (http://creativecommons.org/licenses/by/4.0/).

\begin{abstract}
Three novel coordination polymers $\left\{\left[\mathrm{Cu}_{2}(\mathrm{bitbu}-\mathrm{OMe})_{4}\left(\mathrm{SO}_{4}\right)_{2}\right] \cdot 6 \mathrm{MeOH}\right\}_{\mathrm{n}}(\mathbf{1}),\left\{\left[\mathrm{Co}_{2}\left(\mathrm{bitbu}^{-}\right.\right.\right.$ $\left.\left.\mathrm{OMe})_{4}(\mathrm{NCS})_{4}\right]_{0.5} \cdot 2 \mathrm{DMF}\right\}_{\mathrm{n}}(2),\left\{\left[\mathrm{Co}(\text { bitbu-OMe })_{2}(\mathrm{NCS})_{2}\right] \cdot 2 \mathrm{MeOH}\right\}_{\mathrm{n}}(3)$ (bitbu-OMe = 1, 1' -[(5-tert-butyl2-methoxybenzene-1,3-diyl)dimethanediyl]bis(1H-imidazole)) are synthesized through a slow evaporation method using solvothermal technique of $\mathrm{CuSO}_{4} \cdot 5 \mathrm{H}_{2} \mathrm{O}$ or $\mathrm{Co}(\mathrm{SCN})_{2}$ with bitbu-OMe. Xray diffraction analysis results reveal that 1,2 , and 3 have similar two-dimensional layer networks. The study of the effect of the methoxy group in bitbu-OMe towards the stability of ligand conformation in obtained coordination polymers becomes necessary to be conducted in the future to unveil the reason for conformation similarity of ligand in coordination polymers.
\end{abstract}

Keywords: Coordination Polymer; Bis-Imidazole; Methoxy Group

\section{Introduction}

In recent work, our laboratory has succeeded in developing a two-dimensional coordination polymer prepared from a bis-imidazole ligand called bitb and $\mathrm{CuSO}_{4} .5 \mathrm{H}_{2} \mathrm{O}$. This two-dimensional coordination polymer has the ability to encapsulate perchlorate ions in aqueous solutions by converting their two-dimensional layer network into coordination capsules [1,2]. The development of coordination polymers continued with the development of a chain-like one-dimensional coordination polymer prepared from a bis-benzimidazole ligand having three methoxy groups called bbitrmob and $\mathrm{CuSO}_{4} .5 \mathrm{H}_{2} \mathrm{O}$. This onedimensional coordination polymer has a stable structure as a result of the $\mathrm{C}-\mathrm{H} \cdots \mathrm{O}$ interaction provided by the methoxy group. Single-crystal X-ray diffraction revealed that the chain-like one-dimensional coordination polymer encapsulates a crystalline water molecule within each void [3]. Herein, we report three two-dimensional coordination polymers constructed from a bis-imidazole ligand having a tert-butyl and a methoxy group called bitbu-OMe and reveal their structure characterization.

\section{Materials and Methods}

All reagents and solvents are available commercially and used without further purification. In the part of the syntheses of new multinuclear metal complexes, the slow evaporation method [4] with solvothermal technique [5] is used to grow a single crystal of metal complexes. Single crystal X-ray structure measurement is conducted using Rigaku VariMax with a Saturn diffractometer. Powder X-ray diffraction (PXRD) measurement is conducted using the Rigaku Smart Lab. Nuclear magnetic resonance (NMR) measurement is conducted using JEOL ECA-600 Spectrometer. Elemental analysis (EA) measurement is conducted using Euro Vector EA3000. Fourier transform infrared (FTIR) spectrum is recorded using PerkinElmer FT-IR Spectrometer Frontier. Ultraviolet/Visible (UV/Vis) reflection spectrum is recorded using JASCO V-570 UV/Vis/NIR Spectrometer. 


\section{Results and Discussion}

\subsection{Syntheses of bitbu-OMe}

The bitbu-OMe was first introduced by Qin et al [6]. Here, we report the different way to synthesize bitbu-OMe using different reagents. Imidazole $(2.72 \mathrm{~g}, 40 \mathrm{mmol})$, $\mathrm{NaOH}(3.20 \mathrm{~g}, 80 \mathrm{mmol})$, and THF $(100 \mathrm{ml})$ are added into the round bottom flask. The mixture is stirred at room temperature until the mixture became suspension ( \pm 1 hour). 1,3-bis(bromomethyl)-5-tert-butyl-2-methoxybenzene (7.00 g, $20 \mathrm{mmol})$ in THF (100 mL) is added into the suspension by drop wish. The solution is stirred at room temperature for 2 hours. The orange solution and precipitate are separated by filtration. The precipitate is washed with THF (50 $\mathrm{mL} \times 1)$. The obtained orange solution is evaporated in vacuo. The crude product is dissolved in $\mathrm{CH}_{2} \mathrm{Cl}_{2}(40 \mathrm{~mL})$. The organic solution is washed with water $(100 \mathrm{~mL} \times 3)$ and dried over $\mathrm{MgSO}_{4}$ and filtered. The solution is evaporated in vacuo. The crude product is purified with column chromatography with eluent $\mathrm{CH}_{2} \mathrm{Cl}_{2} / \mathrm{Me}_{2} \mathrm{CO}$ 4:1. The obtained product is evaporated in vacuo. The solid product is recrystallized from $\mathrm{Me}_{2} \mathrm{CO} / \mathrm{H}_{2} \mathrm{O}$. The broken white crystals are obtained.

Yield: $4.63 \mathrm{~g}(71.50 \%) .{ }^{1} \mathrm{H}$ NMR $\left(600 \mathrm{MHz}, \mathrm{DMSO}-\mathrm{d}^{6}\right): \delta=7.70(\mathrm{~s}, 2 \mathrm{H}), 7.14(\mathrm{~s}, 2 \mathrm{H})$, $7.01(\mathrm{~s}, 2 \mathrm{H}), 6.89(\mathrm{~s}, 2 \mathrm{H}), 5.20(\mathrm{~s}, 4 \mathrm{H}), 3.67(\mathrm{~s}, 3 \mathrm{H}), 1.13(\mathrm{~s}, 9 \mathrm{H})$. Elemental analysis (EA) Calcd. For $\mathrm{C}_{19} \mathrm{H}_{24} \mathrm{~N}_{4} \mathrm{O}$ (324.42): C, 70.34; H, 7.46; N, 17.27. Found: C, 70.55; H, 7.34; N, 16.95 .

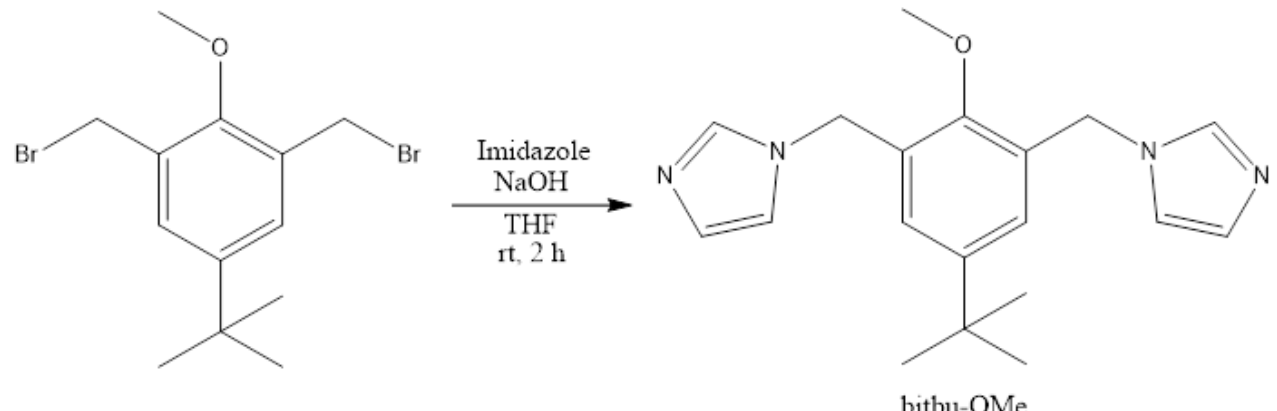

Scheme 1. Scheme of syntheses of bitbu-OMe

\subsection{Syntheses of Novel Coordination Polymers}

\subsubsection{Synthesis of $\left\{\left[\mathrm{Cu}_{2}(\mathrm{bitbu}-\mathrm{OMe})_{4}\left(\mathrm{SO}_{4}\right)_{2}\right] \cdot 6 \mathrm{MeOH}\right\}_{\mathrm{n}}$ (1)}

Single crystals of 1 are prepared by reacting bitbu-OMe and $\mathrm{CuSO}_{4} \cdot 5 \mathrm{H}_{2} \mathrm{O}$. The bitbu$\mathrm{OMe}(0.0648 \mathrm{~g}, 0.200 \mathrm{mmol})$ is diluted in $20 \mathrm{~mL} \mathrm{MeOH}, \mathrm{CuSO}_{4} \cdot 5 \mathrm{H}_{2} \mathrm{O}(0.0250 \mathrm{~g}, 0.100 \mathrm{mmol})$ is diluted in $20 \mathrm{~mL} \mathrm{MeOH.} 2 \mathrm{~mL}$ of each solution is taken, and these solutions taken are mixed in a straight tube slowly for 1 day. Later, purple block crystals are obtained.

The powder of 1 is prepared by reacting bitbu-OMe $(0.0648 \mathrm{~g}, 0.200 \mathrm{mmol})$ diluted in $20 \mathrm{~mL} \mathrm{MeOH}$ and $\mathrm{CuSO}_{4} \cdot 5 \mathrm{H}_{2} \mathrm{O}(0.0250 \mathrm{~g}, 0.100 \mathrm{mmol})$ diluted in $20 \mathrm{~mL} \mathrm{MeOH}$. These solutions are mixed and stirred in $100 \mathrm{~mL}$ round bottom flask for 1 day. Later, purple powder is obtained with yield of $0.0695 \mathrm{~g}(\sim 76.83 \%)$.

\subsubsection{Synthesis of $\left\{\left[\mathrm{Co}_{2}(\text { bitbu-OMe })_{4}(\mathrm{NCS})_{4}\right]_{0.5} \cdot 2 \mathrm{DMF}\right\}_{\mathrm{n}}(2)$}

Single crystals of 2 are prepared by reacting bitbu-OMe and $\mathrm{Co}(\mathrm{SCN})_{2}$. The bitbuOMe $(0.0648 \mathrm{~g}, 0.200 \mathrm{mmol})$ is diluted in $20 \mathrm{~mL} \mathrm{DMF}, \mathrm{Co}(\mathrm{SCN}) 2(0.0175 \mathrm{~g}, 0.100 \mathrm{mmol})$ is diluted in $20 \mathrm{~mL} \mathrm{MeOH.} 2 \mathrm{~mL}$ of each solution is taken, and these solutions taken are mixed in straight tube slowly for 1 week. Later, pink crystals are obtained.

The powder of 2 is prepared by reacting bitbu-OMe $(0.0648 \mathrm{~g}, 0.200 \mathrm{mmol})$ diluted in $20 \mathrm{~mL}$ DMF and $\mathrm{Co}(\mathrm{SCN})_{2}(0.0175 \mathrm{~g}, 0.100 \mathrm{mmol})$ diluted in $20 \mathrm{~mL} \mathrm{MeOH}$. These solutions are mixed and stirred in $100 \mathrm{~mL}$ round bottom flask for 1 week. Later, light pink powder is obtained with a yield of $0.0843 \mathrm{~g}(\sim 86.91 \%)$. 


\subsubsection{Synthesis of $\left\{\left[\mathrm{Co}(\mathrm{bitbu}-\mathrm{OMe})_{2}(\mathrm{NCS})_{2}\right] \cdot 2 \mathrm{MeOH}\right\}_{\mathrm{n}}(3)$}

Single crystals of 3 are prepared by reacting bitbu-OMe and $\mathrm{Co}(\mathrm{SCN})_{2}$. The bitbuOMe $(0.0259 \mathrm{~g}, 0.080 \mathrm{mmol})$ is diluted in $20 \mathrm{~mL} \mathrm{MeOH}$, and $\mathrm{Co}(\mathrm{SCN}) 2(0.014 \mathrm{~g}, 0.080 \mathrm{mmol})$ is diluted in $20 \mathrm{~mL} \mathrm{MeOH.} 2 \mathrm{~mL}$ of each solution is taken, and these solutions taken are mixed in a straight tube slowly for 1 week. Later, pink crystals are obtained.

The powder of 3 is prepared by reacting bitbu-OMe $(0.0648 \mathrm{~g}, 0.200 \mathrm{mmol})$ diluted in $50 \mathrm{~mL} \mathrm{MeOH}$ with $\mathrm{Co}(\mathrm{SCN})_{2}(0.035 \mathrm{~g}, 0.200 \mathrm{mmol})$ diluted in $50 \mathrm{~mL} \mathrm{MeOH}$. These solutions are mixed and stirred in $200 \mathrm{~mL}$ round bottom flask for 1 day. Later, light gray powder is obtained with a yield of $0.0893 \mathrm{~g}(\sim 50.73 \%)$.

\subsection{Structure Characterizations of Novel Multinuclear Metal Complexes}

Single crystal data integration and reduction are conducted using VESTA software [7].

\subsubsection{Structure Characterization of 1}

The single-crystal X-ray diffraction analysis result reveals that $\mathbf{1}$ consists of a twodimensional layer coordination polymer crystallized in the monoclinic system with the space group $P 2{ }_{1}$. $\mathrm{Cu}$ (II) ion (Cu1) has a square pyramidal environment with one oxygen atom (O3) from $\mathrm{SO}_{4}{ }^{2-}$ ligand attached to the axial side of $\mathrm{Cu} 1.1$ becomes neutralized as the result of the coordination bonds between $\mathrm{Cu}(\mathrm{II})$ and $\mathrm{SO}_{4}{ }^{2-}$ ligand. Thus, four nitrogen atoms from four different bitbu-OMe (N1, N4, N5, and N8) are attached to the equatorial side of Cu1. Cu1-N1, Cu1-N4, Cu1-N5, Cu1-N8, and Cu1-O3 distances are approximately $1.997 \AA, 2.018 \AA, 2.010 \AA, 2.017 \AA$, and $2.212 \AA$ Å respectively.

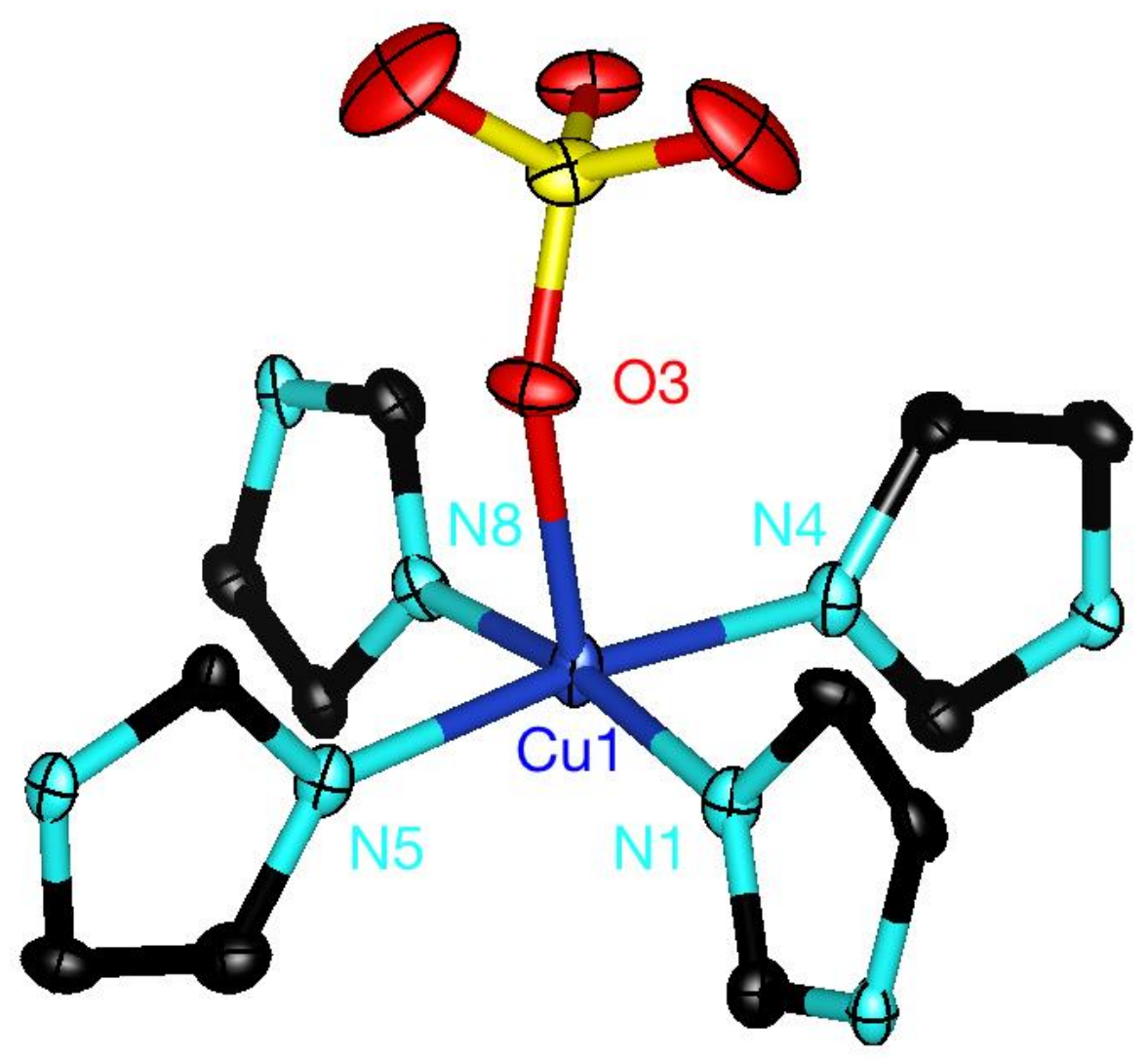

Figure 1. The coordination environment of 1 around the $\mathrm{Cu}(\mathrm{II})$ center represented by thermal ellipsoids of $40 \%$ probability. Hydrogen atoms and solvent molecules are omitted for clarity. Color code: blue, copper; cyan, nitrogen; black, carbon; red, oxygen; yellow, sulfur. 
Table 1. Selected angle [degree] of 1.

\begin{tabular}{cccc}
\hline & Angle & & Degree ( $)$ \\
\hline N1 & Cu1 & O3 & $96.0(2)$ \\
N1 & Cu1 & N4 & $88.9(2)$ \\
N1 & Cu1 & N8 & $168.5(2)$ \\
N1 & Cu1 & N5 & $90.1(2)$ \\
N4 & Cu1 & O3 & $97.6(2)$ \\
N8 & Cu1 & O3 & $95.4(2)$ \\
N8 & Cu1 & N4 & $90.8(2)$ \\
N5 & Cu1 & O3 & $91.4(2)$ \\
N5 & Cu1 & N4 & $171.0(2)$ \\
N5 & Cu1 & N8 & $88.4(2)$ \\
\hline
\end{tabular}

The single-crystal $\mathrm{X}$-ray diffraction analysis result also reveal that $\mathbf{1}$ has rhombic grid style [8]. Interestingly, each $\mathrm{SO}_{4}{ }^{2-}$ ligand results in hydrogen bonding with one crystalline methanol molecule that has hydrogen bonding with another crystalline methanol molecule.

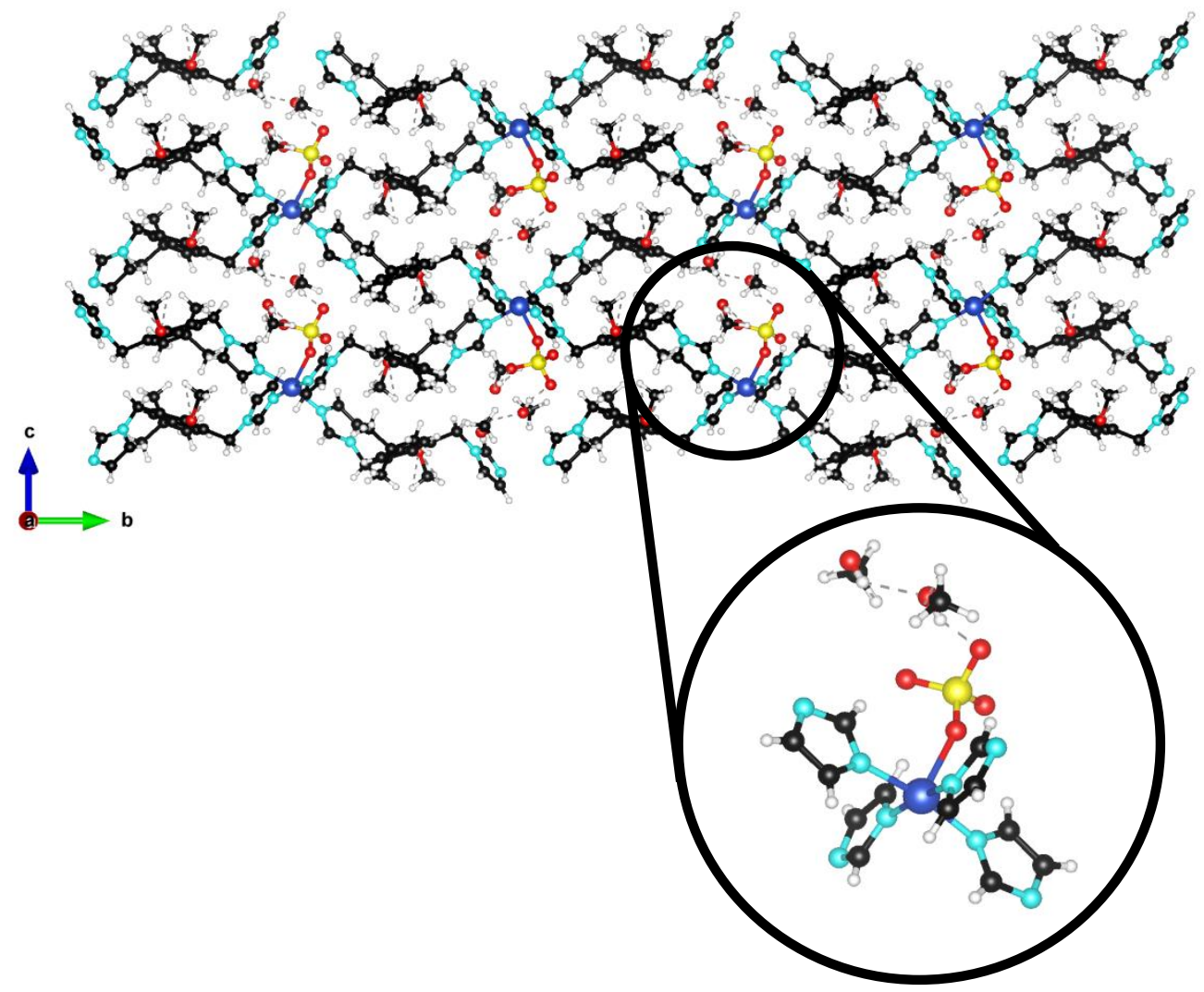

Figure 2. Infinite structures of 1 viewed along an axis. showing hydrogen bonding between $\mathrm{SO}_{4}{ }^{2-}$ ligand and crystalline methanol molecules.

\subsubsection{Structure Characterization of 2}

The single-crystal $\mathrm{X}$-ray diffraction analysis result reveals that $\mathbf{2}$ consists of a twodimensional layer coordination polymer with rhombic grid style [8] crystallized in the monoclinic system with the space group $P 2_{1} / \mathrm{C}$. Co(II) ion (Co1) has an octahedral environment with two nitrogen atoms from two SCN-ligands (N5 and N5*) attached to the axial side of Co1. 2 becomes neutralized as the result of the coordination bonds between $\mathrm{Co}(\mathrm{II})$ 
and two SCN- ligands. Thus, four nitrogen atoms from four different bitbu-OMe (N1, N1*, $\mathrm{N} 4$, and $\mathrm{N}^{*}$ ) are attached to the equatorial side of Co1. Co1-N1 and Co1-N1* have the same distance, which is approximately $2.133 \AA$. Co1-N4 and Co1-N4* have the same distance, which is approximately $2.183 \AA$. Co1-N5 and Co1-N5* have the same distance, which is approximately $2.094 \AA$.

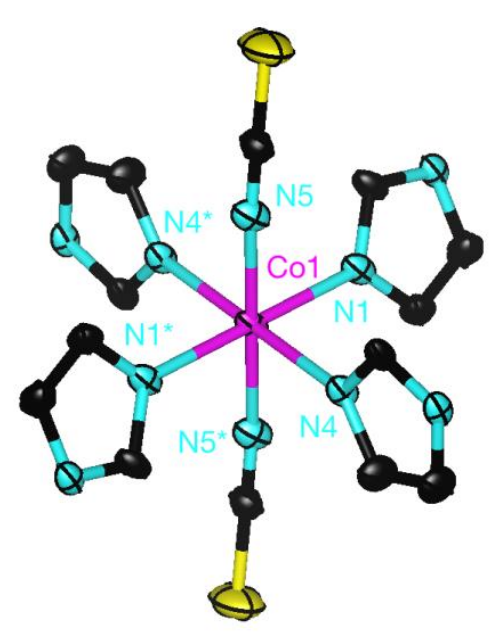

(a)

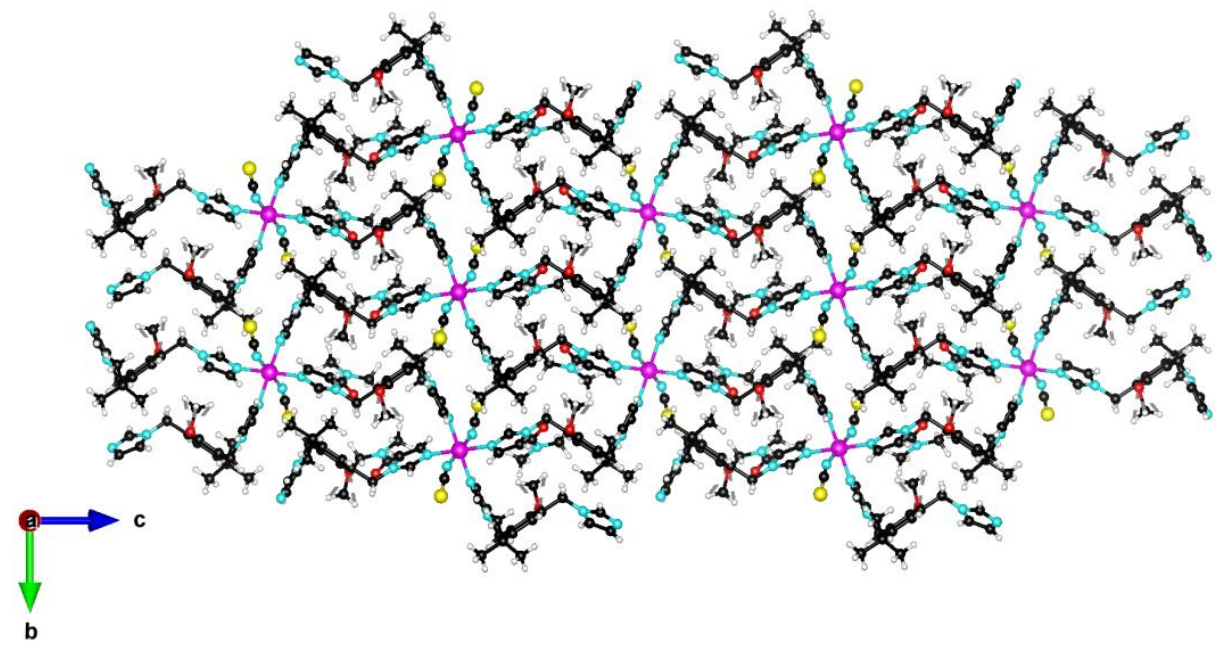

(b)

Figure 3. (a) The coordination environment of 2 around the Co(II) center represented by thermal ellipsoids of $40 \%$ probability. Hydrogen atoms and solvent molecules are omitted for clarity. (b) Infinite structures of 2 viewed along an axis. Color code: magenta, cobalt; cyan, nitrogen; black, carbon; yellow, sulfur.

Table 2. Selected angle [degree] of 2.

\begin{tabular}{|c|c|c|c|}
\hline \multicolumn{3}{|c|}{ Angle } & Degree $\left({ }^{\circ}\right)$ \\
\hline N4 & Co1 & $\mathrm{N} 4^{*}$ & 180.0 \\
\hline N1 & Co1 & $\mathrm{N} 4$ & $89.78(10)$ \\
\hline N1 & Co1 & $\mathrm{N} 4^{*}$ & $90.22(10)$ \\
\hline $\mathrm{N} 1^{*}$ & Co1 & $\mathrm{N} 4$ & $89.78(10)$ \\
\hline $\mathrm{N} 1^{*}$ & Co1 & $\mathrm{N} 4^{*}$ & $90.22(10)$ \\
\hline N1 & Co1 & $\mathrm{N} 1{ }^{*}$ & 180.0 \\
\hline N5 & Co1 & N4 & $89.29(11)$ \\
\hline N5 & Co1 & $\mathrm{N} 4^{*}$ & $90.71(11)$ \\
\hline $\mathrm{N} 5^{*}$ & Co1 & N4 & $90.71(11)$ \\
\hline $\mathrm{N} 5^{*}$ & Co1 & $\mathrm{N} 4^{*}$ & $89.29(11)$ \\
\hline N5 & Co1 & N1 & 90.79 (12) \\
\hline N5 & Co1 & $\mathrm{N} 1^{*}$ & 90.79 (12) \\
\hline $\mathrm{N} 5^{*}$ & Co1 & N1 & $89.21(12)$ \\
\hline N5* & Co1 & $\mathrm{N} 1^{*}$ & $89.21(12)$ \\
\hline N5 & Co1 & $N 5^{*}$ & 180.0 \\
\hline
\end{tabular}

\subsubsection{Structure Characterization of 3}

The single-crystal X-ray diffraction analysis result reveals that 3 consists of a twodimensional layer coordination polymer with rhombic grid style [8] crystallized in the monoclinic system with the space group $P 2_{1} / \mathrm{c}$. Co(II) ion (Co1) has an octahedral environment with two nitrogen atoms from two $\mathrm{SCN}$ - ligands (N5 and $\mathrm{N}^{*}$ ) attached to the axial side of Co1. 3 becomes neutralized as the result of the coordination bonds between Co(II) 
and two SCN- ligands. Thus, four nitrogen atoms from four different bitbu-OMe (N1, N1*, $\mathrm{N} 4$, and $\mathrm{N}^{*}$ ) are attached to the equatorial side of Co1. Co1-N1 and Co1-N1* have the same distance, which is approximately $2.1378 \AA$. Co1-N4 and Co1-N4* have the same distance, which is approximately $2.1461 \AA$. Co1-N5 and Co1-N5* have the same distance, which is approximately $2.1344 \AA$.

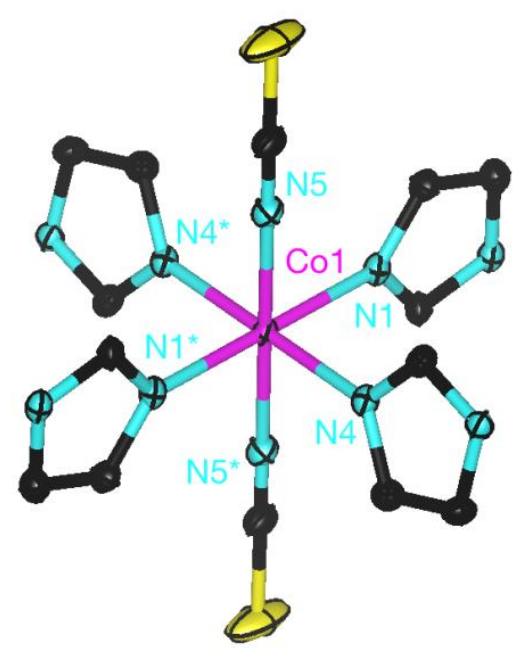

Figure 4. The coordination environment of 3 around the Co(II) center represented by thermal ellipsoids of $40 \%$ probability. Hydrogen atoms and solvent molecules are omitted for clarity. Color code: magenta, cobalt; cyan, nitrogen; black, carbon; yellow, sulfur.

Table 3. Selected angle [degree] of 3.

\begin{tabular}{cccc}
\hline & Angle & & Degree $\left(^{\circ}\right)$ \\
\hline N1 & Co1 & N1 & 180.0 \\
N1 & Co1 & N4 & $90.38(6)$ \\
N1 & Co1 & N4* & $90.38(6)$ \\
N1* & Co1 & N4 & $89.62(6)$ \\
N1* & Co1 & N4 ${ }^{*}$ & $89.62(6)$ \\
N4 & Co1 & N4* & 180.0 \\
N5 & Co1 & N1 & $89.98(7)$ \\
N5 & Co1 & N1* & $90.02(7)$ \\
N5* & Co1 & N1 & $90.02(7)$ \\
N5* & Co1 & N1* & $89.98(7)$ \\
N5 & Co1 & N4 & $89.18(7)$ \\
N5 & Co1 & N4* & $89.18(7)$ \\
N5* & Co1 & N4 & $90.82(7)$ \\
N5 & Co1 & N4 & $90.82(7)$ \\
N5 & Co1 & N5* & 180.0 \\
\hline
\end{tabular}

The single-crystal $X$-ray diffraction analysis result reveals that 3 has voids where each void has an area of approximately $5.37 \AA \times 4.424 \AA$. The length of void is the distance between $\mathrm{C} 1$ and $\mathrm{C}^{*}$ minus the van der Waals diameter of carbon atom, and the width of void is the distance between $\mathrm{N} 3$ and N3* minus the van der Waals diameter of nitrogen atom (Figure 5) by considering the van der Waals modeling with a $100 \%$ radius relativity. 


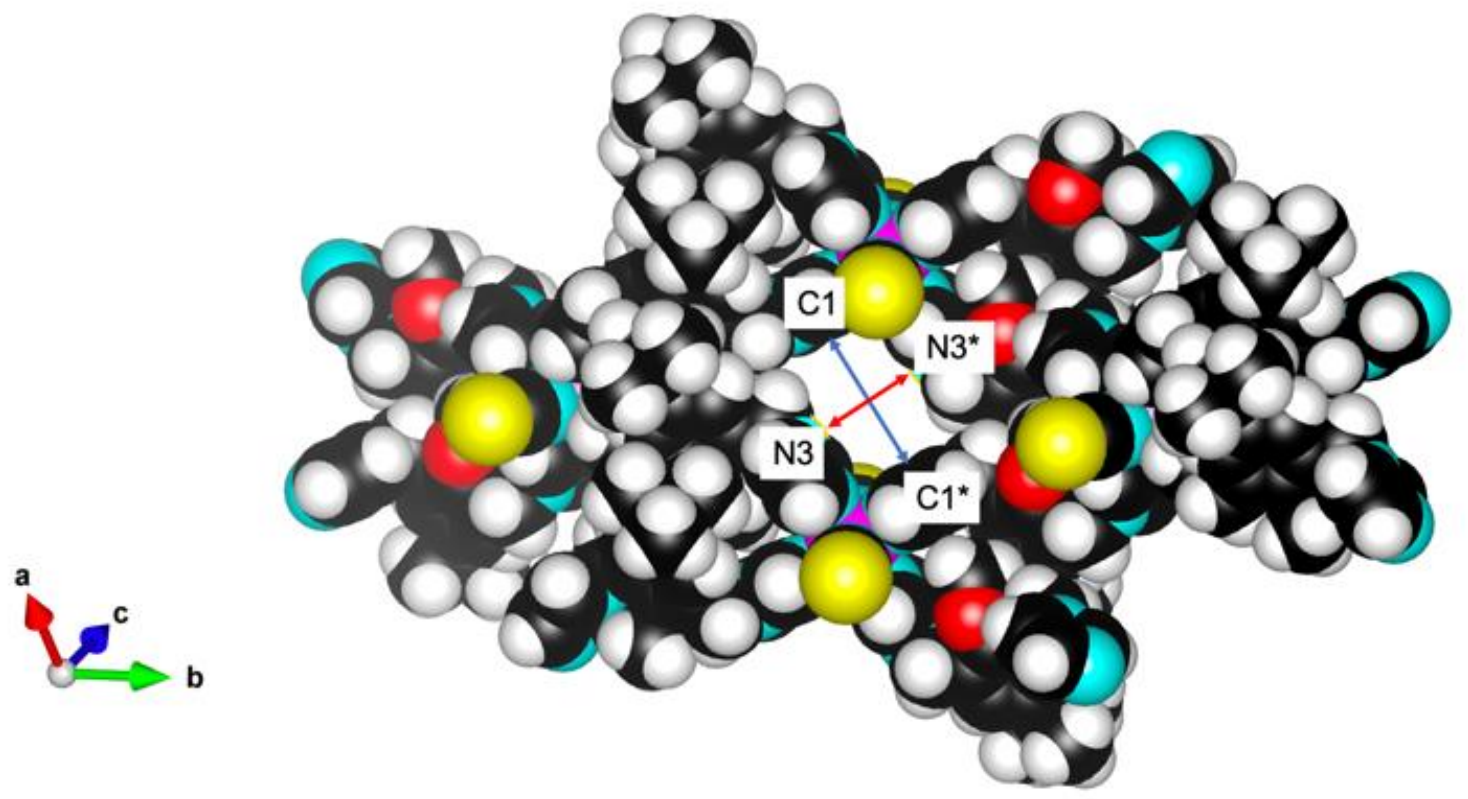

Figure 5. Calculation of the area of void formed in 3. Two methanol molecules in void are omitted for clarity. Color code: magenta, cobalt; cyan, nitrogen; black, carbon; yellow, sulfur.

Interestingly, every void formed in 3 encapsulates two methanol molecules (Figure 6). The investigation of its ability to encapsulate other small organic molecules in terms of water purification becomes necessary to be conducted in the future.

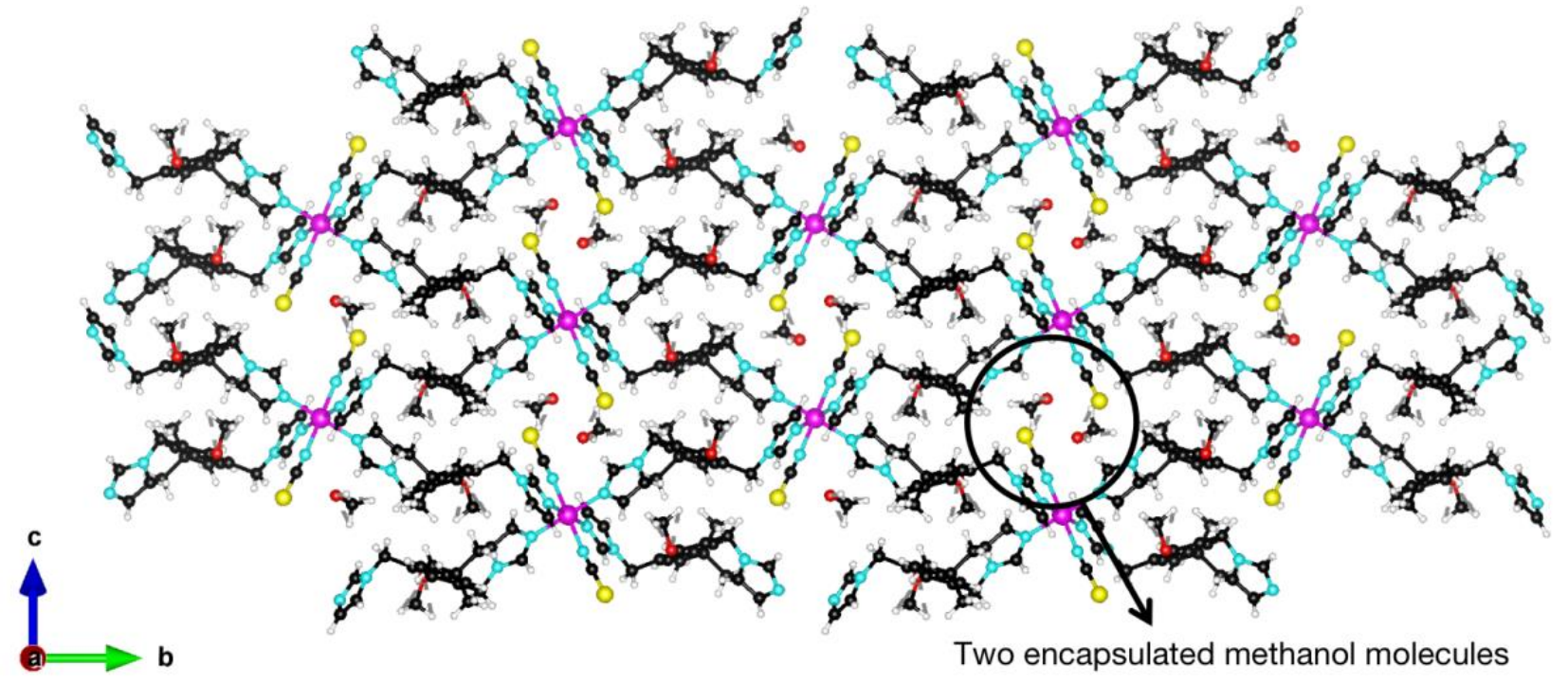

Figure 6. Infinite structures of 3 viewed along an axis showing two methanol molecules encapsulated within each void. 
Table 4. Summary of crystallographic data and structure refinement parameters for 1-3.

\begin{tabular}{|c|c|c|c|}
\hline & 1 & 2 & 3 \\
\hline Empirical formula & $\mathrm{C}_{82} \mathrm{H}_{120} \mathrm{Cu}_{2} \mathrm{~N}_{16} \mathrm{O}_{18} \mathrm{~S}_{2}$ & $\mathrm{C}_{46} \mathrm{H}_{62} \mathrm{CoN}_{12} \mathrm{O}_{4} \mathrm{~S}_{2}$ & $\mathrm{C}_{42} \mathrm{H}_{56} \mathrm{CoN}_{10} \mathrm{O}_{4} \mathrm{~S}_{2}$ \\
\hline Formula weight & 1809.13 & 970.12 & 888.01 \\
\hline Lattice & 'monoclinic' & 'monoclinic' & 'monoclinic' \\
\hline $\mathrm{a}, \AA$ & $9.9795(8)$ & $12.3654(5)$ & $9.9613(3)$ \\
\hline $\mathrm{b}, \AA$ & 23.2115(13) & $9.3458(3)$ & 23.9517(5) \\
\hline c, $\AA$ & 10.0192(9) & 23.0053(9) & $10.2582(3)$ \\
\hline$\alpha,^{\circ}$ & 90 & 90 & 90 \\
\hline$\beta,{ }^{\circ}$ & 112.292(10) & $102.590(4)$ & 113.963(4) \\
\hline$\gamma, \circ$ & 90 & 90 & 90 \\
\hline $\mathrm{V}, \AA^{3}$ & 2147.4(3) & 2594.67(17) & $2236.55(12)$ \\
\hline Space group & P21 (No. 4) & P21/c (No. 14) & P21/c (No. 14) \\
\hline Z & 1 & 2 & 2 \\
\hline $\mathrm{Q}($ calcd $), \mathrm{g} \mathrm{cm}^{-3}$ & 1.399 & 1.242 & 1.319 \\
\hline$\mu(\mathrm{MoK} \alpha), \mathrm{mm}^{-1}$ & 0.621 & 0.463 & 0.529 \\
\hline Radiateon $(\lambda, \AA)$ & 0.71073 & 0.71073 & 0.71073 \\
\hline Temp, K & 173.15 & 173.15 & 173.15 \\
\hline Reflns collected & 9762 & 6941 & 6126 \\
\hline Unique reflns & 7758 & 5573 & 5340 \\
\hline Param refined & 555 & 301 & 273 \\
\hline $\mathrm{R} 1[\mathrm{I}>2 \sigma(\mathrm{I})]$ & 0.0613 & 0.0870 & 0.0556 \\
\hline wR2 [all data] & 0.1665 & 0.2345 & 0.1672 \\
\hline GOF & 1.034 & 1.081 & 1.064 \\
\hline
\end{tabular}

Interestingly, the networks of $\mathbf{1}, \mathbf{2}$, and $\mathbf{3}$ are quite similar, with a rhombic grid system as their network system. The investigation about what causes the network of these coordination polymers to become similar requires further investigation.

\section{Conclusions}

Based on the research result above, three novel coordination polymers have been constructed from bis-imidazole bridging ligand containing a methoxy group and sterical hindrance group tert-butyl called bitbu-OMe. Three two-dimensional rhombic grid network coordination polymers have been constructed from bitbu-OMe, namely $\left\{\left[\mathrm{Cu}_{2}\right.\right.$ (bitbu$\left.\left.\mathrm{OMe})_{4}\left(\mathrm{SO}_{4}\right)_{2}\right] \cdot 6 \mathrm{MeOH}\right\}_{\mathrm{n}}(\mathbf{1}),\left\{\left[\mathrm{Co} 2(\text { bitbu-OMe })_{4}(\mathrm{NCS})_{4}\right]_{0.5} \cdot 2 \mathrm{DMF}\right\}_{\mathrm{n}}(\mathbf{2}),\{[\mathrm{Co}(\mathrm{bitbu}-$

$\left.\left.\mathrm{OMe})_{2}(\mathrm{NCS})_{2}\right] \cdot 2 \mathrm{MeOH}\right\}_{\mathrm{n}}(3)$. The network similarity of these coordination polymers becomes interesting to be investigated in the future to unveil the structure stability factor of them. The presence of two methanol molecules inside of each void formed in 3 becomes evidence that this coordination polymer has the potential to encapsulate small organic matters in aqueous solutions.

Supplementary Materials: The following are available online at https://www.scipublications.com/Supplementary-Materials/84/s1.pdf, Figure S1: (a) ${ }^{1} \mathrm{H}$ NMR spectra of bisimidazole tertbutyl methoxybenzene (bitbu-OMe) in DMSO-d ${ }^{6}$. (b) ${ }^{13} \mathrm{C}$ NMR spectra of bisimidazole tert-butyl methoxybenzene (bitbu-OMe) in DMSO-d6, Figure S2: IR spectrum of bitbu-OMe, Figure S3: IR Spectrum of 1, Figure S4: IR Spectrum of 2, Figure S5: IR Spectrum of 3, Figure S6: UV/Vis/NIR reflection spectrum of 1, Figure S7: UV/Vis/NIR reflection spectrum of 2, Figure S8: UV/Vis/NIR reflection spectrum of 3, Figure S9: (a) Observed PXRD patterns of a bulk sample of 1. (b) The simulated PXRD pattern of $\mathbf{1}$ based on the single crystal X-ray structures. The patterns are shown in the range from $5^{\circ}$ to $60^{\circ}$ for explicit comparison, Figure S10: (a) Observed PXRD patterns of a bulk sample of 2. (b) The simulated PXRD pattern of $\mathbf{2}$ based on the single crystal X-ray structures. The patterns are shown in the range from $5^{\circ}$ to $60^{\circ}$ for explicit comparison, Figure S11: (a) Observed PXRD 
patterns of a bulk sample of 3. (b) The simulated PXRD pattern of 3 based on the single crystal Xray structures. The patterns are shown in the range from $5^{\circ}$ to $60^{\circ}$ for explicit comparison.

Acknowledgments: The first author is thankful to Prof. Mitsuru Kondo from Shizuoka University for providing the opportunity to conduct the research and to provide the laboratory facilities to conduct the measurement.

Conflicts of Interest: The authors declare no conflict of interest.

\section{References}

[1] Kondo, M. Shizuoka University NUC. Perchlorate ion trapping agent. 2012, U.S. Patent 8,101,084.

[2] Hirakawa, T.; Yamaguchi, M.; Ito, N.; Miyazawa, M.; Nishina, N.; Kondo, M.; Ikeya, R.; Yasue, S.; Maeda, K.; Uchida, F. Removal of perchlorate anion from an aqueous solution by encapsulation in an anion-templated self-assembled molecular capsule. Chemistry letters, 2009, 38(3), 290-291.

[3] Narukawa, R.; Kobayashi, T.; Fukunaga, S.; Suzuki, Y.; Kan, T.; Kondo, M. Substituent-controlled Constructions of M2L4 Cage and 1D Network Structures for Cu (II) Complexes with Bis-benzimidazole Ligands. Chemistry Letters, 2020, 49 (7), 832-835.

[4] Aggarwal, M. D.; Batra, A. K.; Lal, R. B.; Penn, B. G.; Frazier, D. O. Bulk single crystals grown from solution on earth and in microgravity. In Springer Handbook of Crystal Growth.; Springer: Berlin, Heidelberg, Germany, 2010; pp. 559-598.

[5] Byrappa, K. Hydrothermal growth of polyscale crystals. In Springer Handbook of Crystal Growth.; Springer: Berlin, Heidelberg, Germany, 2010; pp. 599-653.

[6] Qin, D.B.; Xu, F.B.; Li, Q.S.; Song, H.B.; and Zhang, Z.Z. Synthesis of mixed heterocalixarenes containing imidazolium units. Synlett. 2005, 2005(19), 2987-2989.

[7] Momma, K.; Izumi, F. VESTA: a three-dimensional visualization system for electronic and structural analysis. Journal of Applied crystallography. 2008, 41(3), 653-658.

[8] Robin, A.Y.; Fromm, K.M. Coordination polymer networks with O-and N-donors: What they are, why and how they are made. Coordination Chemistry Reviews. 2006, 250(15-16), 2127-2157. 